20 WHO Collaboration for Drug Statistics Methodology. Guidelines for ATC classification. Oslo: World Health Organisation, 1990.

21 Hardy D, Vogler III J, White R. The shoulder impingement syndrome: prevalence of radiographic findings and correlation with response to therapy. I Radiol 1986;147:557-61.

22 Ozaki J, Fujimoto S, Nakagawa Y, Masuhara K, Tamai S. Tears of the rotator cuff of the shoulder associated with pathological changes in the acromion. f Bone foint Surg [Am] 1988;70:1224-30.
23 Edelson JG, Taitz C. Anatomy of the coraco-acromial arch. $f$ Bone foint Surg [Br] 1992;74:589-94.

24 Tipton CM, Matthes RD, Maynard JA, Carey RA. The influence of physical activity on ligaments and tendons. Med Sci Sports Exerc 1975;7:165-75.

25 Woo SLY, Gomez MA, Woo YK, Akeson WH. Mechanical properties of tendon and ligaments. Biorheology 1982;19:397-408.

(Accepted 12 August 1993)

\title{
Cost analysis of early discharge after hip fracture
}

\author{
William Hollingworth, Chris Todd, Martyn Parker, Jennifer A Roberts, Rhys Williams
}

\begin{abstract}
Objective-To ascertain the economic impact of an early discharge scheme for hip fracture patients.

Design-Population based study comparing costs of care for patients who had "hospital at home" as an option for rehabilitation and those who had no early discharge service available in their area of residence.

Setting-District hospital orthopaedic and rehabilitation wards and community hospital at home scheme.
\end{abstract}

Patients-1104 consecutively admitted patients with fractured neck of femur. 24 patients from outside the district were excluded.

Main outcome measures-Cost per patient episode and number of bed days spent in hospital.

Results-Patients with the hospital at home option spent significantly less time as inpatients (mean of $32.5 v 41.7$ days; $p<0.001$ ). Those patients who were discharged early spent a mean of 11.5 days under hospital at home care. The total direct cost to the health service was significantly less for those patients with access to early discharge than those with no early discharge option $(£ 4884 v £ £ 5606$; $\mathrm{p}=0.048$ ).

Conclusions-About $40 \%$ of patients with fractured neck of femur are suitable for early discharge to a scheme such as hospital at home. The availability of such a scheme leads to lower direct costs of rehabilitative care despite higher readmission costs. These savings accrue largely from shorter stays in orthopaedic and geriatric wards.

Health Services Research Group, Institute of Public Health, University of Cambridge, Cambridge William Hollingworth, research assistant

Chris Todd, senior research associate

Rhys Williams, university

lecturer

\section{Peterborough District}

Hospital, Peterborough

Martyn Parker, research

registrar

\section{Department of Public}

Health and Policy, London

School of Hygiene and

Tropical Medicine,

London

Jennifer A Roberts, senior

lecturer

Correspondence to:

Mr Hollingworth, Health

Services Research Group, Institute of Public Health, University of Cambridge, University Forvie Site, Robinson Way, Cambridge CB2 2SR. out in the patient's home ${ }^{7}$ The surgical treatme hip fracture patients in Peterborough has been described in detail elsewhere. ${ }^{89}$ Briefly, it is based on the principle that, whenever practical, patients should be operated on immediately after admission and mobilised shortly afterwards. Once the postoperative recovery has begun some patients are able to be discharged to the hospital at home scheme. The scheme provides care from trained nurses, nursing auxiliaries, physiotherapists, and occupational therapists in the patient's home for up to 24 hours a day under the medical supervision of the general practitioner. The service also musters social services, meals on wheels, and home helps. The amount of care is tailored to meet the patient's needs, and the scheme is generally continued for up to two weeks before other community services take over.

Previous studies of the early discharge of hip fracture patients showed no significant difference in mortality between the hospital at home group and a comparison group over a 40 month period $^{10}$ and equal return of functional ability at three months. ${ }^{11}$ This paper is a cost analysis comparing patients who had access to hospital at home services as an option for rehabilitation with patients who had no such early discharge scheme available. We focused on direct costs to the NHS and the impact of hospital at home on bed use in the orthopaedic and rehabilitation wards.

\section{Patients and methods}

From 1 January 1987 until 31 December 1991, 1104 patients were admitted to Peterborough District Hospital with a fractured neck of femur. Twenty four of these lived outside the hospital's catchment area and were excluded from the analysis. The remaining 1080 patients were followed up. Information was recorded on variables such as age; functional, ${ }^{12}$ social, ${ }^{13}$ and mental ${ }^{14}$ status; type of treatment received; and length of stay under NHS care.

The hospital at home scheme is currently available only to patients who come from Peterborough city and the villages to the south of Peterborough. Patients resident in Stamford and villages to the north of Peterborough have no early home rehabilitation scheme available. The patients were divided into two groups on this basis.

We used the cost apportionment approach. ${ }^{1516}$ The cost of treatment is broken down into its various components: hotel costs, theatre costs, medical costs, ward costs, overheads, and other treatment expenses. A distinction is then made as to which components vary with length of stay and are therefore the variable costs affected by early discharge.

The resources used by each hip fracture patient were assessed by three methods. Where possible, information on actual individual use of resources-for example, the number of minutes spent in the operating theatre and the cost of the implant each patient received-was used. The nursing time of hospital at home staff and travel costs could also be estimated directly as they are routinely recorded. The large numbers of patients under study meant that detailed individual information could not be recorded for all patients in all aspects of care. For drugs, laboratory 


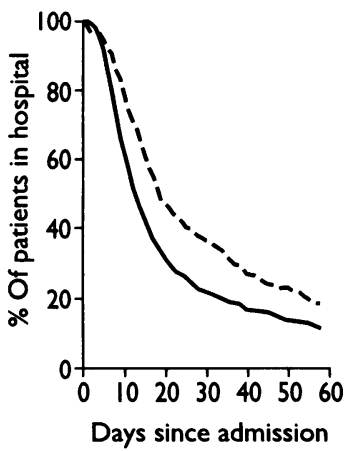

FIG 1-Proportion of patients

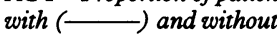
(---) access to early discharge schemes who remained in hospital after hip fracture

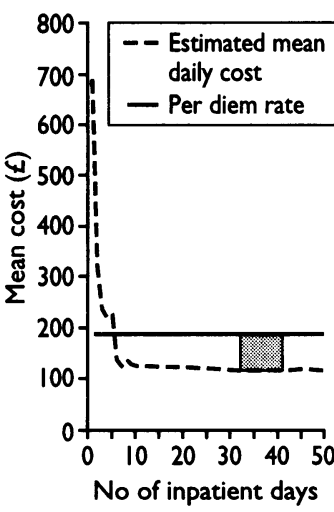

FIG 2-Distribution of inpatien costs. Shaded area represents overestimation had per diem costs been used to calculate benefits of reducing length of stay from 42 to 32 days

investigations, blood transfusion, radiology, electrocardiography, social work, physiotherapy, and occupational therapy the average use by hip fracture patients was estimated by the professionals concerned. Where possible these estimates were validated by reference to a sample of medical records. For shared costs such as hospital records, management, heating, lighting, laundry, and estate the average specialty cost was used. The same average was used for ward costs, medical costs, chiropody, dietetics, and medical photography. Similarly, hospital at home overheads were included as an average per patient.

Some resource areas, such as ward costs, will not be constant throughout a patient's hospital stay. A patient is likely to take up more nursing time during the early days of the stay. This decline in ward costs is important to a study looking at lengths of stay. Care provided to a small group of patients was therefore observed directly at different stages of treatment. ${ }^{17}$ All these costing assumptions are crucial to the final results and were therefore tested in a sensitivity analysis.

All costing information was obtained from the departments themselves or from finance departments of the hospital or the hospital at home scheme and where necessary adjusted to 1991-2 figures. Statistical significance was accepted at the $5 \%$ level; the $t$ test, Mann-Whitney $U$ test, or $\chi^{2}$ test was used.

\section{Results}

Table I presents data on the characteristics of the two groups for factors which have been suggested to influence outcome. ${ }^{18}$ The groups did not differ significantly in age, sex, residence (own home or otherwise) before fracture, haemoglobin concentration, concomitant illnesses, delay before operation, and mobility and activities of daily living scores before fracture. Patients without access to early discharge schemes scored, on

TABLE I-Characteristics of patients admitted with fractured hip

\begin{tabular}{|c|c|c|c|}
\hline & $\begin{array}{l}\text { Patients with access to } \\
\text { hospital at home } \\
\text { scheme } \\
(\mathrm{n}=779)\end{array}$ & $\begin{array}{l}\text { Patients with no access } \\
\text { to early discharge } \\
\text { scheme } \\
(n=301)\end{array}$ & p Value \\
\hline No (\%) of patients discharged to hospital at home & $292(38)$ & 0 & \\
\hline Mean (SD) (years) & $78 \cdot 7(11 \cdot 2)$ & $79.8(10.9)$ & $0 \cdot 14^{\star}$ \\
\hline No $(\%)$ of women & $636(82)$ & $246(82)$ & $0.97 \ddagger$ \\
\hline \multicolumn{4}{|l|}{ Median (interquartile range) test scores: } \\
\hline Mobility (before fracture) & $5(3-9)(n=743)$ & $4(3-9)(n=287)$ & $0.96 \dagger$ \\
\hline Activities of daily living (before fracture) & $33(23-39)(n=431)$ & $33 \cdot 5(26-39)(n=160$ & $0) 0.40 \dagger$ \\
\hline Mental test & $9(5-10)(n=671)$ & $9(7-10)(n=267)$ & $0.04 \dagger$ \\
\hline Mean (SD) haemoglobin concentration & $12 \cdot 34(1 \cdot 7)(n=479)$ & $12 \cdot 24(1 \cdot 7)(n=163)$ & $0.53^{\star}$ \\
\hline Mean (SD) delay in operation (hours) & $29 \cdot 10(38 \cdot 0)(\mathrm{n}=758)$ & $32.6(81 \cdot 4)(n=295)$ & $0 \cdot 34^{\star}$ \\
\hline No (\%) admitted from own home & $560(70)$ & $217(72)$ & $0.46 \ddagger$ \\
\hline Mean (SD) No of concomitant illnesses & $1 \cdot 11(0.94)(n=400)$ & $1.11(0.91)(n=176)$ & $0.94^{\star}$ \\
\hline
\end{tabular}

${ }^{\star} t$ Test. $†$ Mann-Whimey $\mathrm{U}$ test. $¥$ Pearson $\chi^{2}$ test.

TABLE II-Use of selected resource areas by patients treated for fractured hip

\begin{tabular}{lccc}
\hline & $\begin{array}{c}\text { Patients with access to } \\
\text { hospital at home scheme }\end{array}$ & $\begin{array}{c}\text { Patients with no access } \\
\text { to early discharge } \\
\text { scheme }\end{array}$ & $\begin{array}{c}\text { p } \\
\text { Value }^{\star}\end{array}$ \\
\hline Mean $($ SE) inpatient cost $(£):$ & $4591(190)$ & $5606(335)$ & $<0.001$ \\
Inpatient plus hospital at home cost: & $4884(187)$ & $5606(335)$ & 0.048 \\
Breakdown (£(\%) costs) of resource use: & $1556(32)$ & $1943(35)$ & \\
Ward & $293(6)$ & $1434(26)$ & \\
Hospital at home & $1104(23)$ & $703(12)$ & \\
Hotel & $545(11)$ & $640(11)$ & \\
Overheads & $504(10)$ & $457(8)$ & \\
Medical & $455(9)$ & $429(8)$ & $<1.7(3.49)$ \\
Theatre & $427(9)$ & $22.4(1.37)$ & $<0.001$ \\
Other treatment & $32.5(1.98)$ & $18.1(3.17)$ & 0.008 \\
Mean (SE) days of stay: & $16.4(0.72)$ & $0.6(0.32)$ & 0.998 \\
Orthopaedic ward & $13.5(1.71)$ & $0.6(0.26)$ & 0.008 \\
Geriatric ward & $0.5(0.17)$ & & \\
Other ward & $2.2(0.45)$ & & \\
Readmission & & & \\
Hospital at home stay: & $4.3(0.24)$ & & \\
$\quad$ All patients & $11.5(0.36)$ & & \\
Patients actually discharged to hospital at home & & & \\
\hline
\end{tabular}

${ }^{\star}$ Mann-Whitney test. average, significantly better on the mental test. Of the 779 patients who had the early discharge scheme available, $292(37 \cdot 5 \%)$ were discharged to hospital at home and the remainder received usual inpatient rehabilitation.

Figure 1 presents the differences in hospital inpatient stay (excluding readmissions) observed between patients with and without access to early discharge. The groups began to diverge after the fifth day when the first patients were discharged to hospital at home (those going to hospital at home tend to be discharged after an average of 10 days in hospital). One half of the patients who had the early discharge scheme available were discharged from hospital by day 14 compared with day 19 in the other group. However, for some of the group of patients who had the early discharge scheme available a period of hospital inpatient care was substituted by hospital at home care. Patients who were discharged to hospital at home spent a mean of 11.5 days under hospital at home supervision, comprising, on average, 45 hours with a patient aid and 17 hours with more senior nurses. These patients were on average younger (mean 76.0 years $v 80.0$ years; $\mathrm{p}<0.001$ ) and had a higher mobility score before fracture (median $7 v 4 ; \mathrm{p}<0.001$ ) than other patients.

The use of NHS resources per patient episode is summarised in table II. The mean cost per episode was significantly greater for patients without access to early discharge, both when inpatient costs were compared $(£ 5606 v £ 4591 ; \mathrm{p}<0.001)$ and when any hospital at home costs were included ( $£ 5606 v £ 4884 ; \mathrm{p}=0.048)$. These potential financial benefits arise mainly in the areas of ward costs and overheads, which were avoided by patients who spent less time in hospital. In terms of treatment costs-for instance, theatre and implantsthe two groups were similar.

The reduced length of hospital stay for patients discharged to hospital at home releases about 1435 bed days a year (9.2 days per patient), of which 696 days would be on an orthopaedic ward. However, patients resident in the hospital at home area spent significantly longer in hospital as the result of a readmission $(p=0.008), 53(6.8 \%)$ patients being readmitted within one year for reasons related to the fracture, compared with eight $(2 \cdot 7 \%)$ in the other group. Readmission rates within one month of discharge were $4 \%$ and $1 \%$ respectively; most of these patients required revision to surgery.

Figure 2 estimates how the inpatient costs are distributed throughout the patient's stay. Theatre use and intensive postoperative care keep costs high in the early part of a patient's stay and usually decrease postoperatively. The figure highlights the inaccuracy of using easily available average specialty per diem costs $(£ 189)$ when variation in length of stay is being studied. The overestimation that would have occurred in calculating the benefits of reducing length of stay from 41.7 to 32.5 days had these per diem costs been used amounts to about $£ 800$ per patient.

\section{VALIDATION AND SENSITIVITY ANALYSIS}

Direct observations of nursing care provided to five patients early in their postoperative treatment (days 0 to 4) were compared with care to five patients further into their recovery (10 to 15 days) over an eight hour nursing shift each. Early on, patients received a mean of 76 minutes of direct nursing care while later they received 28 minutes. This information on the distribution of ward costs was included in the costing estimations of table II. The orthopaedic registrar and district pharmacist provided an estimate of average drug use by inpatients, which was then costed with the British National Formulary. ${ }^{19}$ This included analgesics and drugs to control nausea $(£ 1 \cdot 72)$, prophylactic antibiotics (cefuroxime $1.5 \mathrm{~g}$ plus three doses of $750 \mathrm{mg}$; 
total cost $£ 12 \cdot 68$ ), intravenous fluids ( $£ 4.80$ ), and a package of commonly used drugs not directly related to the fracture-for example, lactulose- $(£ 7 \cdot 18)$. Although specific drugs varied within the 20 medical records sampled to validate the estimates, the average cost was very close to the original estimate.

The results of the sensitivity analysis in table III show that the results are robust to large changes in the costing information and assumptions. Even if the inpatient costs were $50 \%$ lower than predicted and the hospital at home costs were $50 \%$ higher the results from table II would not be reversed. Similarly the assumption of decreasing ward costs does not influence the overall results.

TABLE III-Sensitivity of results to changes in inputs. Values are mean costs per patient $(\ell)$

\begin{tabular}{lcc}
\hline & $\begin{array}{c}\text { Patients with } \\
\text { access to hospital } \\
\text { at home scheme }\end{array}$ & $\begin{array}{c}\text { Patients with no } \\
\text { access to early } \\
\text { discharge scheme }\end{array}$ \\
\hline $\begin{array}{c}\text { Actual ward costs (constant } \\
\text { throughout stay) }\end{array}$ & $\begin{array}{c}4567 \\
\text { Assumed percentage reduction in estimated hospital }\end{array}$ \\
costs and increase in costs of hospital at home: & \\
25 & 4063 & \\
50 & 3235 & 4457 \\
75 & 2407 & 2160 \\
\end{tabular}

\section{Discussion}

We found that the mean cost of treating patients who had a hospital at home scheme available was significantly less than the cost for patients who had only traditional inpatient rehabilitation available; this result was not sensitive to large changes in costing estimation A total of $37.5 \%$ of patients could be discharged to the hospital at home scheme. Patients who had a hospital at home scheme available spent less time on the orthopaedic and geriatric wards but had more hospital days resulting from readmission than those who had no access to such a scheme. Our calculations showed that using the readily available average specialty cost is likely to produce an inaccurate estimate when length of stay is affected.

A fully randomised study, although perhaps desirable, was not possible in Peterborough, where hospital at home has become the accepted form of rehabilitation. Given this, the findings of this population based study need to be examined with care. The difference between the two populations on mental test score could be one confounding variable, but a lower score for patients with access to hospital at home should increase their cost per episode, which suggests that our results are valid even under this condition.

In figure 1 the continued difference between the two groups at 60 days after admission may well be due to the success of hospital at home in stopping patients becoming institutionalised or acquiring infections while in hospital. Alternatively, the groups could be different on factors not reported in table I such as the relative strengths of community services outside the hospital at home scheme. Our investigation of the obvious confounding variables does not, however, reveal an alternative parsimonious explanation.

Concentrating on cost per episode will not uncover the total impact of hospital at home as it implicitly assumes that the opportunity benefit of the freed beds exactly equals their cost. The 696 bed days freed per year on the orthopaedic ward are likely, however, to be filled by other elective patients. For example, 50 or so hip replacements could be carried out if these beds are available and are managed efficiently. ${ }^{20}$ The hospital is likely to have costs increased by hospital at home because of higher patient throughput. The prospect of higher throughput and costs is likely to act as a disincentive for the hospital to discharge early. This must be taken into account in the joint contract offering the hospital and hospital at home services financial reward for the extra patients treated while ensuring that suitable patients are selected for early discharge. If the contract is successful the benefit of the scheme will be in terms of extra patients treated rather than costs saved. Equally, if it is unsuccessful the freed beds will not be filled and the hospital at home scheme will not save as much as cost per episode suggests, as many resources are fixed and cannot be sold off when not in use.

Table III supports the generalisability of these results to other places in that, even if local costs are very different from those estimated here, the availability of an early discharge scheme is likely to lead to lower direct costs. For similar schemes in other areas it would be important to determine whether $38 \%$ is an attainable target for discharge to hospital at home. Similarly, the scale of the hospital at home service will affect the overall costs and benefits of the scheme. Currently in Peterborough hip fracture patients constitute about $10 \%$ of hospital at home activity. The service is unlikely to be as cost effective in districts where length of stay is already low, although studies in other districts have predicted similar orthopaedic ${ }^{521}$ and total ${ }^{15}$ ward stays.

The higher one month readmission rates in patients who had access to hospital at home care may be a cause for concern about discharging to such a scheme, but the interpretation here is not simple. It is almost inevitable in an early discharge scheme that some complications which would have occurred in hospital now occur at home. These will be classed as readmissions but may bear no relation to the quality of hospital at home care. What is more important is to identify and monitor the underlying complication rates that occur in patients discharged home and those rehabilitated in hospital. Clinical outcomes, reported elsewhere, ${ }^{1011}$ suggest little difference. Thus questions need to be raised about the social, psychological, and economic impact of the scheme.

This paper addresses the economics of early discharge in the NHS, but leaves further research issues. Do patients like the scheme? Is early discharge placing

Financial implications
- The incidence of hip fractures has been
estimated at $45000 /$ year and is predicted to rise
- Hip fracture patients spend long periods
recovering on orthopaedic and geriatric hospital
wards and have in the past been highlighted as
blocking beds
- This study predicts that about $40 \%$ of hip
fracture patients are suitable for early discharge
to the community support provided by hospital
at home services
- Previous studies have suggested little differ-
ence in the clinical outcomes of patients rehabili-
tated in hospital or through hospital at home
schemes; this study shows that the hospital at
home scheme can free six orthopaedic bed days
per hip fracture patient and that this benefit is
not outweighed by the extra cost of the com-
munity scheme
- The value of a scheme such as hospital at
home depends on being able to reuse the hospital
resources which are freed to treat other patients;
this in turn requires the hospital to have ade-
quate funds and theatre space for the extra
patients


an extra economic burden on carers? Is social function maintained better because of hospital at home? Currently we are evaluating hospital at home care in these terms.

We thank the managements of Peterborough District Hospital and the hospital at home service for their support in this study, especially the respective finance departments for supplying the costing information. We are also grateful to members of departments within the district hospital for describing the service they provide, in particular the staff of the orthopaedic wards.

1 Boyce WJ, Vessey MP. Rising incidence of fracture of the proximal femur. Lancet 1985;i:150-1.

2 Central Statistical Office. Social trends. Vol 22. London: HMSO, 1992:27.

3 Campion EW, Jette AM, Cleary PD, Harris BA. Hip fracture: a prospective study of hospital course, complications and cost. 7 Gen Intern Med 1987;2:78-82.

4 Borgquist L, Nordell E, Jarnlo G-B, Stromqvist B, Wingstrand H, Thorngren K-G. Hip fractures in primary health care. Scand $\mathcal{f}$ Prim Health Care K-G. Hip fract

5 Robbins JA, Donaldson LJ. Analysing stages of care in hospital stay for fractured neck of femur. Lancet 1984;ii: 1028-9.

6 The old woman with a broken hip [editorial]. Lancet 1982;ii:419-20.

7 Mowat IG, Morgan RTT. Peterborough hospital at home scheme. $B M \mathcal{J}$ $1982 ; 284: 641-3$
8 Parker MJ, Myles JW, Anand JK, Drewett R. Cost-benefit analysis of hip fracture treatment. $f$ Bone foint Surg $[\mathrm{Br}]$ 1992;74B:261-4.

Pryor GA, Myles JW, Williams DRR, Anand JK. Team management of the elderly patient with hip fracture. Lancet 1988;i:401-3.

10 Todd CJ, Williams DRR, Pryor GA, Parker MJ, Myles JW. Early discharge to "hospital at home" after fracture of neck of femur: psychosocial factors. In: Brenner G, Weber I, eds. Health services research and primary health care. Köln: Deutscher Ante-Verlag, 1991:185-90.

11 Pryor GA, Williams DRR. Rehabilitation after hip fractures. $\mathcal{f}$ Bone foint Surg [Br] 1989;71B:471-4

12 Parker MJ, Pryor GA, Myles JW. Early discharge after hip fracture. Acta Orthop Scand 1991;62:563-6.

13 Townsend P. The last refuge. London: Routledge and Kegan Paul, 1962.

14 Hodkinson HM. Evaluation of a mental test score for assessment of mental impairment in the elderly. Age Ageing 1972;1:233-8.

15 Drummond MF. The principles of economic appraisal in health care. Oxford: Oxford Medical Publications, 1980

16 Russell EM. Patient costing study. Edinburgh: Scottish Home and Health Department, 1974. (Scottish Health Service Studies No 31.)

17 Reid N, Robinson G, Todd C. The quantity of nursing care on wards working 8-hour and 12-hour shifts. Int 9 Nursing Studies 1991;28:47-54

18 Greatorex IF, Gibbs ACC. Proximal femoral fractures: some determinants of outcome. 7 Epidemiol Community Health 1988;42:365-9.

19 British National Formulary. No 22. London: British Medical Association, Royal Pharmaceutical Society of Great Britain, 1991.

20 Sommers LS, Schurman DJ, Jamison JQ Woolson ST, Robison BL, Sommers LS, Schurman D, Jamison JQ Woolson ST, Robison BL,
Silverman JF. Clinical-directed hospital cost management for total hip arthroplasty patients. Clin Orthop 1990;258:168-75.

21 Office of Population and Census Surveys. Hospital in-patient enquiry. London: HMSO, 1987

(Accepted 17 August 1993)
Yorkshire Trauma Audit Group

Participants in the study are listed at the end.

Correspondence to:

Mr N Zoltie, Clinical

Information Science Unit,

Leeds University, 22 Hyde

Terrace, Leeds

LS2 9LN.

BM 1993;307:906-9

\title{
The hit and miss of ISS and TRISS
}

\author{
N Zoltie, F T de Dombal on behalf of the Yorkshire Trauma Audit Group
}

\section{Abstract}

Objective-To measure interobserver variation in recording injury from case notes and its effect on calculating injury severity scores (ISS) from identical data and predicting probabilities of survival by using the combined trauma and injury severity score (TRISS).

Design-Observer variation study using injury severity scoring and subsequent calculation of probability of survival based on combined trauma and injury severity scores.

Subjects-16 patients with a range of injury severity scores, and 15 observers.

Results-There was a wide variation in recorded injury severity scores, the probability of two observers agreeing on the score being $0.28(28 \%)$. The probability of any two observers agreeing over which severity band the patient should be in was $0.5(50 \%)$. Observer variation was independent of the training and type of observer. Survival probability (calculated by combined trauma and injury severity scoring methodology from individual observers' scores) varied by over 0.2 in six of the 16 patients and by over 0.5 in three.

Conclusions-There is wide observer variation in injury severity scoring, which highlights a potential fallibility in its use for trauma audit. The use of combined trauma and injury severity scoring for individual prediction of survival is potentially inaccurate except at the extremes of probabilities. The use of the 0.5 survival line on a combined trauma and injury severity score "pre-chart" is statistically and clinically inappropriate.

\section{Introduction}

As a consequence of the recommendation of the Royal College of Surgeons Working Party, ${ }^{1}$ increasing numbers of centres are conducting trauma audit. From time to time results are published for comparison and scrutiny. ${ }^{23}$ The usual methodology used is the combined trauma and injury severity scoring system (TRISS), ${ }^{4}$ which consists of calculations based on the injury severity score (ISS) and the revised trauma score (RTS). We report an observer variation study to establish the reliability and reproducibility of injury severity scoring and to ascertain what effect any variation might have on calculations of the probability of survival by means of combined trauma and injury severity scoring.

\section{Patients and methods}

Data from case notes of patients entered into the United Kingdom major trauma outcome study ${ }^{5}$ from one hospital were used. As a completely unselected series might have resulted in a skewed distribution of injury severity scores measures were taken to ensure a wide spread of scores.

Patients began entering the United Kingdom major trauma outcome study on 1 April 1990, and data from the first 30 were screened. We selected the first four patients with low injury severity scores $(0-20)$, as judged by the values actually entered into the United Kingdom major trauma outcome study; the first four patients with middle range scores (21-40); and the first four patients with high scores (41-75). Four other patients were selected at random so that observers would not know the exact numbers in each "group." Sixteen was the maximum number of cases that observers were thought able to code without time or fatigability problems. At that stage of selection neither other details (type of injury, area of injury, number of injuries) nor final outcome (death or survival) was known.

The case notes of the 16 patients were collected in their entirety and given to 15 observers for coding, no observer having knowledge of any other person's scores. Coding was carried out between January and July 1991. The observers were five accident and emergency consultants, six accident and emergency senior registrars, one accident and emergency registrar, and three trauma audit clerks. The observers were informed that there would be a range of severity and asked to identify every anatomical injury, code the injury (using the six figure code of abbreviated injury 